\title{
Políticas públicas federais de turismo: uma análise circunstancial do Plano Nacional de Turismo 2003-2007 (Brasil)
}

\section{National politics publishes of tourism: one rapid analysis of National Tourism}

Plain 2003-2007 (Brazil)

\author{
Jhonattan Souza da Rocha (ROCHA, J. S. da R.) * e \\ Noslin de Paula Almeida (ALMEIDA, N. de P.) ${ }^{* *}$
}

\begin{abstract}
RESUMO - Este trabalho aborda o entendimento do papel do poder público na sociedade através das políticas públicas. Apresenta um breve histórico das políticas de turismo no Brasil, os direcionamentos e regulamentações que precedem a política atual. Comenta as ações propostas pelo Plano Nacional de Turismo realizadas pelo recém criado Ministério do Turismo, suas metas visando geração de emprego, de renda, o aumento do turismo interno, a diversificação da oferta e o número de turistas estrangeiros. Analisa também os macroprogramas criados para dar suporte e criar condições para atingir as metas previstas. Nas considerações finais a percepção do que foi discutido e o que pode ser melhorado.
\end{abstract}

Palavras-chave: Programas; Metas; Objetivos; Sustentabilidade e desenvolvimento.

ABSTRACT - This work approaches the agreement of the paper of the power publishes in the society through the politics publishes. It presents a briefing historical of the politics of tourism in Brazil, the aiming and regulations that precede the current politics. It comments the actions proposals through the National Cloth of Tourism to be carried through for the just bred Ministry of the Tourism, its goals that aim at income, job generation, the increase of the internal tourism, the diversification of the offers and the number of foreign tourists. It also analyses the macro programs created to give support and to create condition to get the foreseen goals. In the final considerations the perception of what it was argued and what can be improved.

Key words: Programs; Goals; Objectives; Sustentability and development.

\footnotetext{
* Bacharel em Turismo e Professor Substituto do Curso de Turismo da UFMS - Universidade Federal de Mato Grosso do Sul. Endereço: Rua Antonio Campello, 997 - Aquidauana/MS. CEP: 79.200-000. Telefones: (67) 3241-0412 e 9204-7416. Email: jhonattantur@ hotmail.com

** Bacharel em Turismo, Mestre em Desenvolvimento Local e Professor Assistente do Curso de Turismo da UFMS. Endereço: Rua Dr. Arthur Jorge, 2276 (Ap. 201) - Campo Grande/MS. CEP: 79.010-210 Telefones: (67) 3301-7807 e 9912-5579. Email: noslin@cpaq.ufms.br
} 


\section{INTRODUÇÃO}

Mais um mandato presidencial no país encerrou-se no ano de 2006. Um bom momento para analisar as ações, os programas de governo, os projetos desenvolvidos nos últimos anos, e mais ainda, refletir sobre o empenho e o compromisso assumido. Pela primeira vez o Brasil pôde contar com uma pasta própria, um ministério específico e um plano de âmbito nacional voltado para o turismo.

Analisar o desenvolvimento do turismo brasileiro nos últimos anos e as ações do MTUR - Ministério do Turismo é uma oportunidade para observar os caminhos que tomaram as suas diretrizes político-administrativas estabelecidas, principalmente as metas alcançadas e projetos desenvolvidos. Uma análise acadêmica e imparcial dessas políticas pode vir a contribuir para uma maior compreensão dos fatos e umas percepções qualificadas dos fatores que influenciaram as tomadas de decisões, além de proporcionar uma maior reflexão à importância da política pública para o turismo e para o meio acadêmico.

A análise em questão reconhece que todo processo de planejamento, seja ele turístico ou não, é feito em momentos e caracterizado segundo as ideologias desses momentos, por isso a dificuldade de continuação de planos ou projetos de governos antecessores.

O objetivo principal deste trabalho é analisar quais foram as ações e diretrizes adotadas após 2003, observando, nesse período, os programas executados e as metas estabelecidas no PNT - Plano Nacional de Turismo. Compreender como aconteceu a evolução das políticas de turismo no Brasil, as regulamentações, o desenvolvimento e o fomento da atividade, através do estudo dos relatórios e dos documentos referenciais apresentados pelo MTUR.

O turismo vem acontecendo no mundo há muito tempo, mas o Brasil ainda dá seus primeiros passos na busca por fazer da atividade um dos seus propulsores de desenvolvimento. É fato que o país tem potencial para ser um dos maiores destinos turísticos do mundo. Busca-se então perceber como a gestão pública atua neste sentido, compreendendo a importância das políticas públicas de turismo no país, e qual o direcionamento das práticas atuais através do PNT. Na definição de Beni (1998, p. 99), observa-se o que se pode compreender como políticas públicas: 
[...] conjunto de fatores condicionantes e diretrizes básicas que expressam os caminhos para atingir os objetivos globais para o turismo do país; determinam as prioridades da ação executiva supletiva ou assistencial do estado, facilitam o planejamento das empresas do setor quanto aos empreendimentos e as atividades mais susceptíveis de receber apoio estatal. Ela deverá nortear-se por três grandes condicionantes; o cultural, o social e o econômico, por mais simples que sejam os programas, os projetos e as atividades a desenvolver, por maiores ou menores que sejam as áreas geográficas em que devam ocorrer, quaisquer que sejam suas motivações principais ou setores econômicos aos quais possam interessar.

O Estado tem como atribuição formular políticas de assistência às necessidades da sociedade, portanto, as políticas de turismo devem estar condicionadas a esse interesse maior, suas diretrizes e objetivos precisam ser direcionados para que dentro de um contexto econômico, social e cultural atendam aos interesses da sociedade de modo geral, conforme observa Dias (2003, p. 127):

\footnotetext{
As leis, projetos e resoluções, ou seja, as normas codificadas no direito são um importante instrumento para a realização de políticas públicas [...] elas estabelecem regras, limites, impõem condições, barram privilégios etc; que são fundamentais para organização turística desde a elaboração de passaportes, até a criação de uma taxa de acesso a um recurso natural criada por uma municipalidade, a regulamentação do turismo é uma das mais importantes ações que podem ser empreendidas pelo Estado em seus diferentes níveis de organização.
}

Ao referir-se sobre a importância da regulamentação turística como ferramenta, o autor coloca os diferentes níveis de organização governamental que podem empreender na construção de uma regulamentação da atividade turística, que seriam as políticas na esfera federal, na estadual e as municipais, ressaltando que num passado muito próximo apregoou-se a municipalização dos destinos turísticos.

\section{POLÍTICAS PÚBLICAS DE TURISMO E SEU HISTÓRICO NO BRASIL}

Embora em 1938 tenha acontecido a primeira intervenção do Estado na regulamentação turística do país, onde o decreto $\mathrm{n}^{\circ}$. 406/38 que dispunha sobre autorização do Estado para a comercialização de passagens aéreas marítimas ou terrestres foi o decreto $n^{\circ}$. 55/66 que marcou como o "salto" para a nova organização turística brasileira. Pela primeira vez foram criadas diretrizes para uma política nacional 
de turismo, além da criação da EMBRATUR, na época denominada Empresa Brasileira de Turismo e do CNTUR - Conselho Nacional de Turismo, sendo este o principal antecedente histórico do sistema organizado da atividade turística, pois surge no Brasil uma estrutura federal de administração do turismo, complementada por uma política nacional de turismo, com atribuições e objetivos estabelecidos de forma genérica. Vale destacar a importância de se fazer a regulação da atividade como forma de proteger os interesses públicos como afirma Beni (2006, p. 115).

A qualidade das regras, isto é, sua capacidade de proteger os interesses públicos em sintonia com a realidade e a sinalização de aperfeiçoamentos futuros expressa o avanço do processo democrático. As regras são essenciais para oferecer referencias e criar as condições de previsibilidade para os investimentos. Além das normas especificas sobre turismo, as regras referentes aos temas de ordenamento, serviços, posturas, dentre outros, são essenciais para o turismo.

A criação da EMBRATUR em 1966 foi um marco positivo na história das regulamentações, em seguida a criação do FUNGETUR - Fundo Geral do Turismo, que como Dias (2003, p. 131) coloca, tinha como objetivo prover recursos para o financiamento de empreendimentos, obras e serviços de finalidade e interesses turísticos e seria administrado pela EMBRATUR. Foi o primeiro fundo especialmente criado para financiar o desenvolvimento turístico do país. Porém não marcou o fim das políticas errôneas e do mau entendimento do governo sobre como melhor aproveitar o turismo.

Como evidencia Boiteux (2005, p. 33-34), ao comentar sobre o decreto $\mathrm{n}^{\circ}$. 2.294/86, que torna a atividade turística livre no país, ou seja, sem a necessidade de registro, mantendo apenas fiscalização e classificação, na prática, qualquer um poderia doravante dedicar-se ao turismo, mesmo que de maneira oportunista como aconteceu com as agências de viagens. Recorda que em vez de criar uma mudança de percepção no quadro do aprimoramento da prestação de serviços, um verdadeiro "caos" turístico foi implantado no país.

Ainda segundo Boiteux (2005, p. 39), em 1991 acontece a reformulação da EMBRATUR.

O governo Collor promoveu em 1991 através da lei $n^{\circ}$. 8.181 mudanças na atividade turística revogando o decreto 55/66 [...] a primeira modificação sem dúvida alguma foi a nova denominação da Embratur agora Instituto Brasileiro de Turismo e que também passou a ter sede e foro na capital federal". 
Caberia então formular a política nacional de turismo, coordenando sua execução seja propondo normas e medidas ao Governo Federal ou cumprindo com as determinações estabelecidas. Um Plano Nacional de Turismo no Brasil só aconteceu de fato, em 1995 no governo de Fernando Henrique Cardoso. Foi neste mesmo governo que aconteceu a implantação do PNMT - Programa de Municipalização do Turismo, do então Ministério da Indústria, Comércio e Turismo, que tinha como objetivo fomentar o desenvolvimento dos municípios com bases para a sustentabilidade econômica, social, ambiental, cultural e política.

Para alcançar os objetivos propostos, o PNMT organizou-se em torno de cinco grandes ações estratégicas: definir e difundir por todos os meios que estivessem ao seu alcance, os princípios básicos norteadores do processo de municipalização do turismo; elaborar e aplicar metodologia, apropriada à realidade brasileira para o desenvolvimento do turismo sustentável; estabelecer uma rede de agentes multiplicadores e instituições parceiras para a operacionalização do programa; envolver as comunidades locais através da realização de oficinas e encontros, com aplicação de técnicas de enfoque participativo; e apoiar os municípios nas iniciativas que tinham por finalidade o fortalecimento institucional e na elaboração de planejamento estratégico para o desenvolvimento do turismo sustentável.

Os objetivos específicos do PNMT esclarecem os cinco princípios propostos como norteadores das ações do plano, descentralização, sustentabilidade, parcerias, mobilização e capacitação.

O plano proposto e executado durante o governo de Fernando Henrique Cardoso se resume em transferir para os governos municipais a responsabilidade de acreditar e investir no turismo. Cabe à esfera federal somente oferecer suporte técnico, de informação e capacitação. Recursos para infra-estrutura e fomento da atividade seriam de responsabilidade também dos governos municipais, o que na teoria pode até parecer ter sido bom, mas que na prática foi bastante contraditório, pois a grande maioria dos municípios brasileiros têm dificuldades para manter suas estruturas básicas sociais (saúde, educação, moradia).

Os custos para o desenvolvimento da atividade são elevados e os benefícios chegam somente ao longo prazo, oportunizando somente o beneficio à empresários estrangeiros que pouco contribuem para o desenvolvimento das comunidades onde se 
inserem, e acabam por promover as desigualdades, a segregação, exclusão social, a deformação e destruição de culturas e formas de organização social.

A criação do MTUR, órgão de administração direta do Governo Federal, serviu para a articulação com os demais ministérios, governos estaduais, municipais, poder legislativo, com o setor empresarial e a sociedade organizada, integrando as políticas públicas e o setor privado.

Com a estrutura organizacional do MTUR, onde cabe a este órgão a função de elaborar as políticas e de disponibilizar os recursos tanto de capital quanto de informação e gestão, auxiliado pelo CNTUR, pelo Fórum dos Secretários Estaduais de Turismo e dividido em duas secretarias, a de políticas e a de programas, além da EMBRATUR. Ainda, mesmo com essa nova estrutura funcional e organizacional para o turismo Beni (2006, p. 31) aponta:

\begin{abstract}
Se por um lado o MTUR apresenta hoje uma estrutura institucional correta e apta a planejar o espaço turístico nacional com diretrizes norteadoras e estruturantes do processo de regionalização do turismo, por outro os estados e municípios ainda enfrentam enormes dificuldades e obstáculos para entender, aplicar, operacionalizar e dar continuidade, em seus limites políticos territoriais às diretrizes prescritas e aplicáveis em suas respectivas conjunturas.
\end{abstract}

Para Beni (2006, p. 28-33) o principal problema do turismo brasileiro é a falta de posicionamento do mercado, e para corrigir essa ausência de visão estratégica é preciso examinar as variáveis que entram na escala de produção do setor a fim de traçar cenários futuros com planejamento, logística e redução de riscos. O pensamento estratégico é resultado do estímulo à visão sistêmica e global do mundo.

Já para o MTUR (2006, p. 50), em documento referencial denominado "Turismo no Brasil - 2007/2010”, elaborado com a colaboração das entidades participantes do Conselho Nacional de Turismo e amplamente divulgado, essas dificuldades ou empecilhos, como colocado, apresentam-se de duas formas: o primeiro estaria relacionado à falta de recursos humanos qualificados para absorver, entender e interpretar a metodologia adotada, no sentido de harmonizá-la e compatibilizá-la à realidade local, bem como os instrumentos operacionais disponíveis. O segundo estaria na grande incapacidade institucional para a gestão e planejamento do turismo. A 
qualificação de recursos humanos é um tema que deve ser solucionado rapidamente com a dedicação dos poderes e com o crescimento dos estudos e pesquisa em turismo.

Para exemplificar a complexidade da análise do sistema do turismo no cenário brasileiro, pode-se considerar que a sociedade é dividida em ambientes para que se estabeleça o entendimento das relações e da dinâmica de uso e ocupação do espaço e dos bens de consumo. Percebendo ainda que o ambiente econômico é o centro da sociedade, pois no sistema capitalista é em torno dele que as relações acontecem.

O ambiente político tem o papel de estabelecer uma superestrutura capaz de direcionar e fomentar ações para a criação e desenvolvimento de dois tipos de infraestrutura: a básica que compreende as necessidades mínimas dos padrões de vida atual (saneamento básico, água, luz esgoto, saúde, educação, segurança) e a segunda que é a infra-estrutura específica, no caso do turismo, os aeroportos, hotéis, centros de convenções, vias de acesso, controle de qualidade etc.

A criação, recuperação e desenvolvimento dessas infra-estruturas devem acontecer de forma planejada para manter um equilíbrio entre os outros ambientes da sociedade, o ecológico (água, solo, ar, praias, parques, cachoeiras, montanhas), o ambiente econômico como o centro das relações responsável pela dinâmica das ações (emprego, renda, produção, consumo) e o ambiente cultural social que é dividido em dois grupos, as pessoas e o patrimônio cultural.

O patrimônio cultural é dividido em dois tipos: o material e o imaterial, que correspondem a praças, prédios, livros, museus, quadros, estátuas e os hábitos e costumes respectivamente. A comunidade é dividida em três tipos: a local, a empreendedora e os turistas, observando que existem relações entre eles e entre os ambientes. (DIAS; AGUIAR, 2002, p. 130).

No caso do turismo ele se apropria dos dois tipos de infra-estrutura do ambiente ecológico, das pessoas e do patrimônio cultural e estabelece uma dinâmica de relações entre todos. Portanto, verifica-se a dificuldade em se manter um equilíbrio nas ações de forma que todos os segmentos sociais sejam beneficiados, já que é esta a função da política pública.

Portanto, percebe-se a existência de uma complexidade para formular planos, projetos e propostas que agradem tanto aos turistas, quanto a uma comunidade local e a 
uma comunidade empreendedora, tanto em ações de nível federal quanto às de nível estadual e municipal.

Nem toda parcela da população é beneficiada pelo turismo ou está envolvida diretamente, aliás, para a promoção e o desenvolvimento da atividade só uma mínima parcela dessa população tem participação efetiva na condição de empreendedor, para a grande maioria restam apenas os benefícios indiretos do turismo. Exemplo é a cidade de Bonito/MS, reconhecido destino de ecoturismo do país, onde se percebe claramente em conversas informais com moradores que, a parcela da população não envolvida diretamente com o turismo reclama da atividade e do alto custo de vida, e os empregos para aqueles que não são empreendedores ajudam a promover o desequilíbrio social, a especulação imobiliária e afasta as pessoas para a periferia.

As práticas e políticas atuais ainda não conseguiram ultrapassar muitas barreiras, também porque ainda existe a idéia de que as políticas de turismo englobam todas as outras políticas sociais, como educação, saúde, e que com o turismo esses que muitas vezes são verdadeiros enclaves sociais não existirão ou desaparecerão. $\mathrm{O}$ turismo deve ser encarado de maneira profissional e por pessoas capacitadas e aptas a formular estratégias para sua promoção e desenvolvimento.

Existe uma relação de interdependência das metas propostas, sendo que à medida que uma vai acontecendo, vai estimulando o desenvolvimento da outra e assim sucessivamente, o mesmo acontece no processo inverso, onde se uma meta não se desenvolver acaba atrapalhando o andamento da outra. Sendo assim, não é possível aumentar o número de empregos se não aumentar a oferta, esta necessita de uma demanda efetiva para sobreviver. Não é possível aumentar a geração de divisas se a demanda estiver estagnada, diferente do que foi apresentado pelo Ministério do Turismo nos balanços divulgados, onde apontou que só uma das cinco metas não seria alcançada.

A justificativa de que o Brasil só não conseguiria aumentar o número de turistas estrangeiros visitando o país foi a de que "a crise da Varig prejudicou a atividade". Uma justificativa que trata as metas de forma isolada, o que na prática não acontece. Tem-se como exemplo disso o programa de micro-crédito que foi uma das grandes promessas de campanha do atual governo federal, e só começou a sair do papel no último ano do primeiro mandato, ainda assim, depois de muita pressão. 
Outro ponto em que o governo se contradiz na execução de programas diz respeito à ampliação da oferta turística, onde propôs a criação de 81 produtos de qualidade internacional a serem apresentados no Salão Brasileiro do Turismo em junho de 2005 em São Paulo. A questão levantada é a de que se precisa levar em consideração a diferença entre recurso e produto turístico. Segundo Beni (2006, p. 93), "Recursos são elementos disponíveis na localidade turística ou com potencial turístico passível de ser explorado de acordo com a legislação vigente". O Brasil possui uma grande diversidade de recursos naturais para o turismo. O mesmo autor complemente ainda que: "Produto turístico é o resultado final dos equipamentos e serviços agregados aos recursos, principalmente os naturais".

\begin{abstract}
A velocidade com que se pretendeu criar ao menos três produtos turísticos brasileiros por Estado da federação parece que nos levou a uma precipitação conceitual que insiste equivocadamente em se perpetuar. A roteirização pode servir momentaneamente para o marketing dos destinos e ampliar o fluxo turístico para algumas regiões em curto prazo, mas de maneira alguma é o caminho para estabelecer e consolidar o turismo como instrumento de desenvolvimento sustentável. BENI (2006, p. 32)
\end{abstract}

Como bem abordou o autor, toda a ideologia de um desenvolvimento turístico baseado na sustentabilidade e no equilíbrio fica comprometida, ainda porque, sempre foi bastante frisado pelo mesmo, que a comercialização de qualquer destino deveria ser antecedida de estruturação, quer seja quanto à prestação dos serviços turísticos, quanto à estruturação básica de ordem das políticas públicas.

\title{
3 MACRO PROGRAMAS PARA A GESTÃO DO TURISMO BRASILEIRO
}

Os macros programas eram construídos por um conjunto de programas que visavam transpor os obstáculos que impedem o crescimento do turismo no Brasil, identificados por um processo de consulta ao setor, foram apresentados sete macros programas em 2003, sendo eles:

1. Gestão e Relações Institucionais - Tinha por objetivo acompanhar, apoiar e dar encaminhamento às recomendações do CNTUR, das Câmaras Temáticas e do Fórum Nacional de Secretários e Dirigentes Estaduais de Turismo e acompanhar as 
ações dos fóruns estaduais de turismo nas 27 Unidades da Federação (UF), de modo a viabilizar a realização do sistema de gestão descentralizado da Política Nacional de Turismo, proposto no PNT e incentivar a organização das instâncias macrorregionais de turismo.

2. Fomento - Pretendia estimular o desenvolvimento da atividade através da atração de investimentos e do financiamento para o turismo popular.

3. Infra-estrutura - A falta de infra-estrutura é um dos grandes, senão, o maior limitador para o crescimento do turismo. Este macro programa foi estruturado, principalmente no Programa de Desenvolvimento Regional do próprio MTUR, onde visava melhorar a qualidade de vida nas cidades turísticas; criar condições para implantação de equipamentos turísticos; facilitar o acesso de fluxo de turistas; e, equilibrar o desenvolvimento das regiões brasileiras.

4. Estruturação e diversificação da oferta - Visava a regionalização dos destinos turísticos através do programa "Roteiros do Brasil" alicerçado nos ideais de arranjos produtivos, baseava-se nas parcerias, na gestão descentralizada, interiorização e segmentação da atividade, diversificação dos mercados e produtos.

5. Qualidade do produto turístico - Visava a normatização da atividade e a qualificação profissional.

6. Apoio a comercialização - Foram estabelecidos dois planos de marketing para o país sendo um voltado ao mercado interno "Plano Cores do Brasil" e outro voltado ao mercado internacional "Plano Aquarela" além de ser criada e instituída a "Marca Brasil" para representar o país e os principais atributos de exportação.

7. Informações turísticas - Para o Ministério do Turismo é necessário um programa contínuo que pesquise não só a oferta turística, mas também a demanda, além de um sistema que permita uma avaliação dos impactos do turismo na economia e os benefícios para a sociedade. Também se faz necessário, um maior suporte às ações de promoção, comercialização e as tomadas de decisão do poder público.

\section{CONSIDERAÇÕES FINAIS}

Ao acompanhar as noticias e matérias publicadas todos os dias nos principais veículos de comunicação do país percebe-se que a atividade turística continua crescendo 
e muito por todo o mundo, sendo uma promissora forma de organização social e de desenvolvimento. $\mathrm{O}$ Brasil realmente possui potencial para que a atividade aconteça em todo o território nacional, principalmente pela sua diversidade de fauna, flora, história e cultura. Entretanto, este artigo procurou compreender o papel do poder público, e o rumo das suas ações propostas pelo governo federal até o ano de 2006.

Este artigo também pontuou a busca pela descentralização das decisões no turismo proposta pelo PNMT. Na ocasião o governo acreditou que os municípios seriam capazes de desenvolver o turismo se tivessem incentivos, técnicos e de informação somente. Perceberam então, que os incentivos financeiros são tão importantes quanto os técnico-científicos, pois, são raros os municípios que tem têm condições de fazer investimentos partindo somente da sua receita natural. O turismo através de uma visão sistêmica e como uma atividade complexa, requer ser estudada e pesquisada para o estabelecimento de estratégias e diretrizes para sua promoção.

O turismo proposto de maneira séria e profissional como um gerador de emprego, renda, promovendo o equilíbrio social e a diminuição das desigualdades, como pode ser lido no texto do Plano Nacional de Turismo é a atividade ideal. Porém, adotou-se como estratégia principal o Plano de Regionalização, com o propósito de se criar pólos e roteiros turísticos (mínimo três por estado), mesmo que de maneira um pouco precipitada, já que o ideal seria a estruturação e a acessibilidade aos destinos e produtos já disponibilizados, oferecendo não só quantidade, mas também uma qualidade maior dos produtos.

O turismo brasileiro nos últimos quatro anos que antecederam 2007 passou por dificuldades. A crise do transporte aéreo! Setor que vinha em um ritmo de crescimento acelerado, com médias acima de $15 \%$ nos últimos anos. Sendo que este é um dos setores fundamentais na atividade principalmente para emissão de turistas estrangeiros, e também dos vôos domésticos, haja vista que o Brasil é um país de dimensões continentais.

Conclui-se que o turismo pode sim ser uma alternativa de vida para regiões e pessoas até então segregadas pelo mundo globalizado e pelo capitalismo. A maioria dos entraves que dificultam o desenvolvimento da atividade no país é de conhecimento do poder público e o que falta realmente é vontade e esforço político pra fazer acontecer, principalmente realizando pesquisas mais voltadas à busca de qualidade do que a 
apresentação de números à sociedade. Deve-se realmente preparar a população para participar dos processos de tomada de decisão.

Valorizar de maneira mais equilibrada as cidades brasileiras oferecendo oportunidades para que várias delas estejam inseridas no mercado de forma competitiva, descentralizando de São Paulo e Rio de Janeiro. Propor metas reais, condizentes com as expectativas e projeções do país, e principalmente regulamentar a atividade e os setores que ela agrega para evitar desperdício de recursos, desperdício de mão-de-obra e a informalidade.

\section{REFERÊNCIAS:}

BENI, M. C. Política e planejamento de turismo no Brasil. São Paulo: Aleph, 2006. Análise estrutural do turismo. São Paulo: Senac, 1998.

BOITEUX, B. do C. Legislação de turismo: tópicos de direito aplicados ao turismo. 2. ed. Rio de Janeiro: Elsevier, 2005.

DIAS, R. Planejamento do turismo: política e desenvolvimento do turismo no Brasil. São Paulo: Atlas, 2003.

DIAS, R.; AGUIAR, M. R. Fundamentos do turismo: Conceitos, normas e definições. Campinas: Alínea, 2002.

MINISTÉRIO DO TURISMO. Plano Nacional de Turismo. Brasília, 2006. Disponível em: <www.turismo.gov.br>. Acesso em: 10/01/2007a.

. Turismo no Brasil 2007-2010. Brasília, junho 2006. Disponível em: <www.turismo.gov.br>. Acesso em: 10/01/2007b.

Recebido em: 04 de novembro de 2007

Aprovado em: 04 de dezembro de 2007 